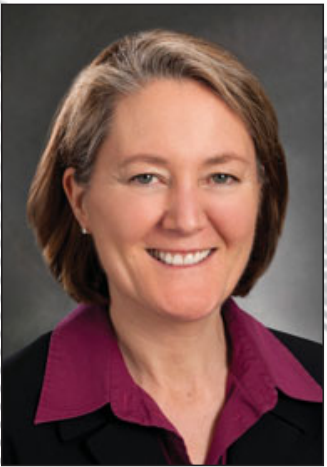

Tia Benson Tolle

2014 MRS President

\section{Venturing beyond technology toward sustainability}

\author{
www.mrs.org/sustainability/
}

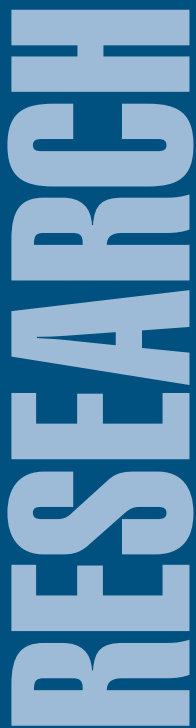

Today, more and more people are becoming conscious of their responsibility to provide a sustainable world for future generations. The materials community is doing its part by promoting the strong link between materials research and sustainable global development, and conducting research that can truly enhance global sustainability. We often reference the Materials Research Society's (MRS) Mission to "promote communication for the advancement of interdisciplinary materials research and technology to improve the quality of life." Sustainability will clearly impact the quality of life for generations to come.

Because our members span the globe and represent the breadth of the materials endeavor across multiple disciplines and sectors worldwide, MRS is well-positioned to take a leadership role to support materials scientists, engineers, and society in promoting the sustainable sourcing, development, production, application, and reuse of materials. Materials are at the heart of the sustainability issue, and our members are uniquely geared to offer their talents, education, and voices to address the challenges.

For the past several years, there clearly has been an increasing emphasis within the Society on materials and materials science for a sustainable world. Last year, our Public Outreach Committee began working on a project to succeed the Strange Matter museum exhibition, which is currently traveling the globe and raising awareness of the importance of materials. As the successor project was developed, the focus quickly evolved into one of materials and sustainability, and the concept for Strange Matter Green Earth (SMGE) was born. The international SMGE project team is in the early planning, pre-development, and funding campaign stages, but from the outset has been focused on global perspectives and community-based STEM learning opportunities for our planet's sustainability.

This is not our first effort in this area-MRS Meetings have a long history of sustainabilityfocused forums and symposia. MRS has also published two special issues of the MRS Bulletin focused on Materials for Sustainable Development (April 2012) and Harnessing Materials for Energy (April 2008); a new textbook titled Fundamentals of Materials for Energy and Environmental Sustainability; and launched a new journal (MRS Energy \& Sustainability - A Review Journal) in mid-2014. These activities and products are described in more detail on the MRS Sustainability Resources website http://www.mrs.org/sustainability/.

As we move forward with the promotion of sustainability, there will be more opportunities for our members to get involved. During the 2014 MRS Fall Meeting, there will be a palette of sustainability-related activities to serve our members and like-minded partners. The program will begin on Sunday with an afternoon tutorial titled Materials for Sustainable Development 
in which three leaders in the field will survey the role of materials in sustainability, methods for designing a product to minimize its ecological footprint, and critical material for energy applications. And we will reach beyond our meetings attendees, capturing key sessions on MRS OnDemand $^{\circledR}$, making them easily available to the community at any time after the Meeting, as well as for those who cannot attend this year's sessions.

On Monday, Symposium FF, Materials as Tools for Sustainability, will begin with invited speakers who will cover topics that include an overview of the role of materials research in sustainability, opportunities for funding, ways to engage the public in discussions about complicated issues, and the rationale behind the growing corporate social responsibility activities in which many companies are engaged. Symposium FF will continue throughout the week, while in parallel there will be opportunities to attend and participate in a roundtable discussion with industry sustainability professionals in the Technology Innovation Forum and in a rollout of prototypes of SMGE exhibit elements. There will also be an opportunity to learn about a new college-level lecture course called Impact of Materials on Society that is being developed for international dissemination by the University of Florida faculty in partnership with the MRS Public Outreach Committee.

\section{$\mathrm{M}|\mathrm{R}| \mathrm{S} \bigcirc \mathrm{OnDemand}{ }^{\circledR}$}

MRS OnDemand ${ }^{\circledR}$ is a service to the community that features rich content from MRS Meetings and other relevant resources, complete with video, audio, and presentation materials.

\section{www.mrs.org/on-demand}

I encourage all of our members and attendees to take advantage of this programming and to venture beyond our specific technology sessions and routines at the 2014 MRS Fall Meeting and explore the fascinating and critically important issues associated with the science and engineering of sustainable technologies. You'll also want to check out the Sustainability Resources website and the many links to the Society's sustainability-related efforts. If you are interested in learning about how you can become more involved and do not see what you are looking for on the site, please contact Richard Souza, Manager, Education and Outreach, at souza@mrs.org.

I think that you'll be impressed by the ways in which the MRS membership is contributing to the development of a sustainable future. I hope that you will be inspired to weave this awareness into your own research efforts, encourage others to do the same, and join your fellow MRS members and volunteers in developing future symposia, publications, outreach, and education programs.

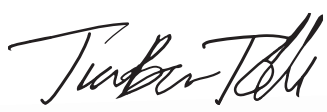

Tia Benson Tolle 2014 MRS President

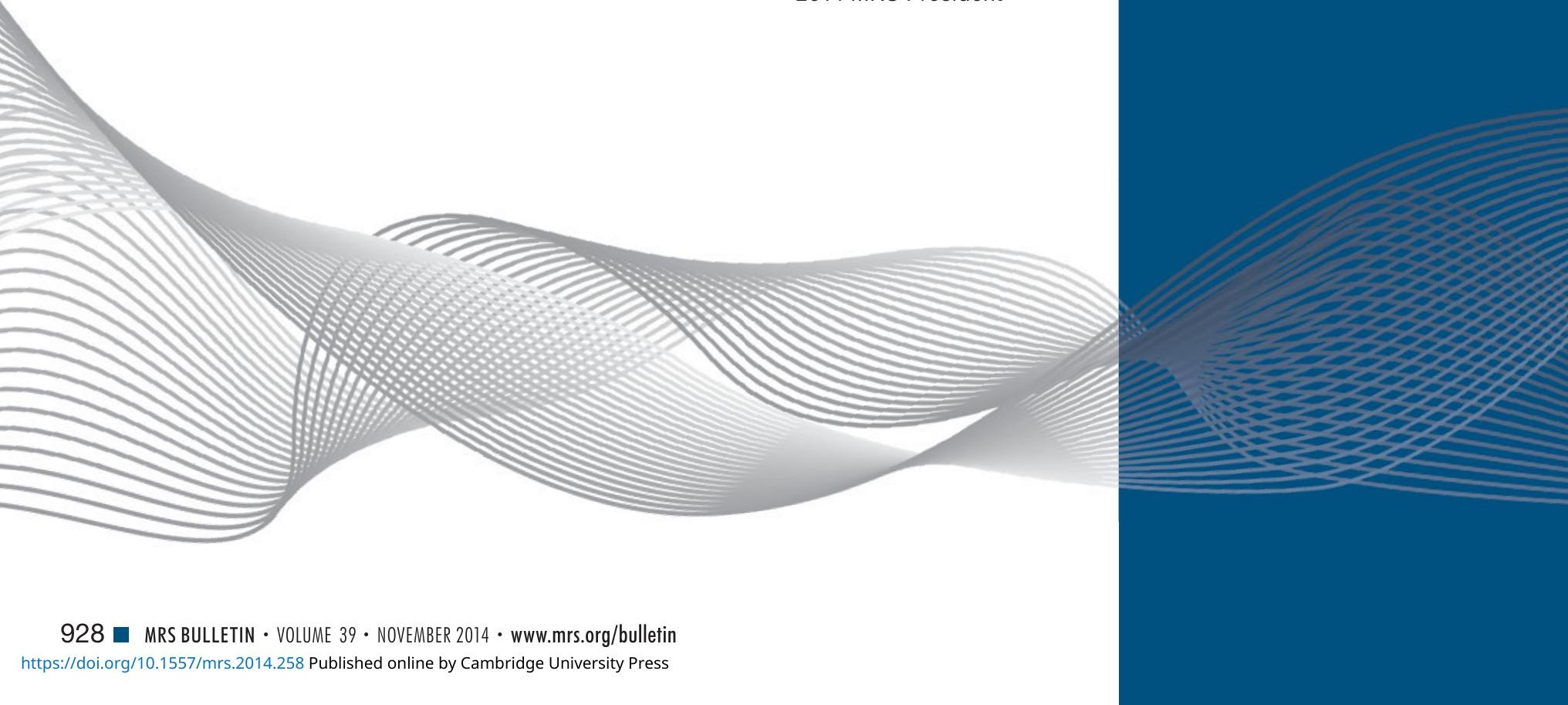

